\title{
Curcumin Inhibits Lung Cancer Cell Invasion and Metastasis through the Tumor Suppressor HLJ1
}

\author{
Huei-Wen Chen, Jen-Yi Lee, Ji-Ying Huang, ${ }^{1}$ Chi-Chung Wang, ${ }^{4}$ Wan-Jiun Chen, \\ Sheng-Fang Su, ${ }^{1}$ Chia-Wen Huang, ${ }^{1}$ Chao-Chi Ho, ${ }^{2}$ Jeremy J.W. Chen, \\ Meng-Feng Tsai, ${ }^{6}$ Sung-Liang Yu, and Pan-Chyr Yang ${ }^{2}$
}

'Department and Institute of Pharmacology, School of Medicine, National Yang-Ming University, ${ }^{2}$ Department of Internal Medicine,

National Taiwan University Hospital and National Taiwan University Medical College, and ${ }^{3}$ Department of Clinical Laboratory Sciences and Medical Biotechnology, College of Medicine, National Taiwan University, Taipei, Taiwan; ${ }^{4}$ Graduate Institute of Basic Medicine, Fu Jen Catholic University, Taipei, Taiwan; and 'Institute of Biomedical Science and Molecular Biology, College of Life Sciences, National

Chung-Hsing University, Taichung, Taiwan; and ${ }^{6}$ Department of Molecular Biotechnology, Da-Yeh University, Changhua, Taiwan

\begin{abstract}
Curcumin (diferuloylmethane) is an active component of the spice turmeric and has a diversity of antitumor activities. In this study, we found that curcumin can inhibit cancer cell invasion and metastasis through activation of the tumor suppressor DnaJ-like heat shock protein 40 (HLJ1). Human lung adenocarcinoma cells (CL1-5) treated with curcumin (1-20 $\mu \mathrm{mol} / \mathrm{L})$ showed a concentration-dependent reduction in cell migration, invasion, and metastatic ability, and this was associated with increased HLJ1 expression. Knockdown of HLJ1 expression by siRNA was able to reverse the curcumininduced anti-invasive and antimetastasis effects in vitro and in vivo. The $H L J 1$ promoter and enhancer in a luciferase reporter assay revealed that curcumin transcriptionally upregulates $H L J I$ expression through an activator protein (AP-1) site within the HLJ1 enhancer. JunD, one of the AP-1 components, was significantly up-regulated by curcumin (1-20 $\mu \mathrm{mol} / \mathrm{L})$ in a concentration- and time-dependent manner. Knockdown of JunD expression could partially reduce the curcumin-induced HLJ1 activation and diminish the anti-invasive effect of curcumin, indicating that JunD would seem to be involved in curcumin-induced HLJ1 expression. Curcumin was able to induce c-Jun $\mathrm{NH}_{2}$-kinase (JNK) phosphorylation, whereas the JNK inhibitor (SP-600125) could attenuate curcumin-induced JunD and HLJ1 expression. Activation of HLJ1 by curcumin further leads to up-regulation of E-cadherin and a suppression of cancer cell invasion. Our results show that curcumin induces HLJ1, through activation of the JNK/JunD pathway, and inhibits lung cancer cell invasion and metastasis by modulating E-cadherin expression. This is a novel mechanism and supports the application of curcumin in anti-cancer metastasis therapy. [Cancer Res 2008;68(18):7428-38]
\end{abstract}

\section{Introduction}

Curcumin (diferuloylmethane), an active component of the spice turmeric, is able to suppress cancer cell proliferation, invasion,

Note: H-W. Chen and J-Y. Lee contributed equally to this work.

Part of the study has been published by Lee JY as the poster in 2006 AACR Annual Meeting in Washington, DC, P1322.

Requests for reprints: Pan-Chyr Yang, Department of Internal Medicine, National Taiwan University Hospital and National Taiwan University Medical College, No.7, Chung-Shan South Road, Taipei, 100, Taiwan. Phone: 886-2-23562185; Fax: 886-223224793; E-mail: pcyang@ntu.edu.tw and Huei-Wen Chen, 155, Li-Nong Street, Taipei, Taiwan. E-mail: hwchen@ym.edu.tw.

c) 2008 American Association for Cancer Research.

doi:10.1158/0008-5472.CAN-07-6734 angiogenesis, and metastasis (1) through a diversity of signaling pathways involving nuclear factor- $\kappa \mathrm{B}, \mathrm{I} \kappa \mathrm{B} \alpha$ kinase, Akt, activator protein (AP-1), mitogen-activated protein kinase, cyclooxygenase-2 (COX-2), lipoxygenase, inducible nitric-oxide synthase, urinary plasminogen activator, tumor necrosis factor, chemokines, cell surface adhesion molecules, cyclin D1, and others (2-5). Human clinical trials have indicated no dose-limiting toxicity when curcumin is administered at doses up to $10 \mathrm{~g} /$ day and when the serum concentration of curcumin was $1.77 \pm 1.87 \mu \mathrm{mol} / \mathrm{L}$ at the dose of $8 \mathrm{~g} /$ day (6). These studies suggest that curcumin may have enormous potential in cancer therapy. However, a better understanding of the mechanisms of the drug would enhance the therapeutic potential of curcumin either alone or in combination with other anticancer therapy. This might be possible by synergistically modulating several of the properties of cancer such as proliferation, invasion, and metastasis. To provide a more global perspective, we examined the anticancer mechanisms of curcumin using cDNA microarray mRNA analysis of lung cancer cells and identified a panel of candidate curcumin target genes (7). Some of these target genes are highly associated with the cancer invasion and metastasis (8).

Interestingly, one of the target genes is a heat shock protein (HSP), HLJ1, also known as DNAJB4, which was recently cloned and classified as a member of the HSP40 family (HSP40/DnaJ; ref. 9). HSPs are thought to act as molecular chaperones. They can be powerfully induced by heat shock and other chemical and physical stresses in a wide range of species $(10,11)$. Recently, it has been found that some HSPs are associated with progression in a variety of human cancers and may modulate cancer cell proliferation, differentiation, invasion, metastasis, and apoptosis $(12,13)$. Some HSPs have been suggested as able to serve as diagnostic or prognostic biomarkers and may also be useful as new targets for anticancer drug development (14).

The novel candidate target of curcumin, HLJ1, belongs to HSP40 family, which occurs throughout the cell and shows a high diversity in eukaryotic genomes (15). They are at least 44 genes present in the human genome (16). We have previously reported that HLJ1 as able to inhibit lung cancer cell proliferation, anchorage-independent growth, tumorigenesis, cell motility, invasion, and cell cycle progression. High expression of HLJI in tumor specimens is associated with reduced cancer recurrence and longer overall survival of non-small cell lung cancer (NSCLC) patients (17). The endogenous control of $H L J 1$ transcription in cancer cells is regulated by transcriptional factor YY1 and AP-1 (18). This new tumor suppressor and invasion suppressor HLJ1 may be a potential treatment target for anticancer therapy (19). 
Several lines of evidence have shown that curcumin is able to inhibit cancer cell invasion and metastasis $(3,7,20,21)$, and our previous microarray data suggested that not only the metalloproteinase (MMP) could be affected by curcumin, but also the tumor suppressor and invasion suppressor HLJ1 may be regulated by curcumin (7). In this study, we identified that the anti-invasive and antimetastasis effect of curcumin is mediated by up-regulation of HLJ1 and curcumin is able to transcriptionally regulated HLJ1 expression through the JNK/JunD pathway and inhibit lung cancer cell invasion and metastasis by modulating E-cadherin expression.

\section{Materials and Methods}

\section{Cell Lines and Culture Conditions}

The human lung adenocarcinoma cell lines with less invasive (CL1-0) and highly invasive capacities (CL1-5) were established previously (22). The human lung carcinoma cell line, A549 [American Type Culture Collection (ATCC); CCL-185], was obtained from ATCC. The cells were grown in DMEM (Life Technologies) supplemented with $10 \%$ fetal bovine serum (FBS; Life Technologies) and each of penicillin and streptomycin $(100 \mathrm{mg} / \mathrm{mL}$ each) at $37^{\circ} \mathrm{C}$ in a humidified atmosphere of $5 \% \mathrm{CO}_{2}(7)$.

\section{Migration Assay}

Cancer cell migration was assayed by wound-healing assay and transwell migration assay as described previously with some modification $(7,17)$.

The wound-healing assay. The cancer cells were cultured in 24-well plates and grown in medium containing $10 \%$ FBS to nearly confluent cell monolayer, then carefully scratched using a plastic pipette tip to draw a linear "wound" in the cell monolayer of each well. The monolayer was washed twice with PBS to remove debris or the detached cells from the monolayer, and then curcumin was added by different concentrations $(1,5,10$, and $20 \mu \mathrm{mol} / \mathrm{L})$; the control well was added with $0.1 \%$ of DMSO as the solvent control. The cultures were incubated at $37^{\circ} \mathrm{C}$ and photographed immediately and monitored by time lapse (photographed per $20 \mathrm{~min}$ for $12 \mathrm{~h}$ ) in the Carl Zeiss Axiovert 200M/COOLSANP $f x$ with Bio-station system (Carl Zeiss). Under the microscope, the number of cells that migrated into the cell-free zone, base on the zero line of the linear "wound," was evaluated. The experiments were performed thrice in triplicate and were counted double blind by at least two investigators.

The transwell migration assay. The cancer cell transwell migration assay was performed according to our previous study and partially modified (7). Briefly, Transwell membrane (8- $\mu \mathrm{m}$ pore size, $6.5-\mathrm{mm}$ diameter; Corning Costar Corporation) was used. The CL1-5 cells were trypsinized, washed, and kept suspended in medium without FBS. To the lower wells of the chambers, migration-inducing medium (with 10\% FBS) were added. Upper wells were filled with serum-free medium with cells $(20,000$ cells per well), in some cases, also containing different concentrations of curcumin ( 1,5 , 10 , and $20 \mu \mathrm{mol} / \mathrm{L}$ ) or $0.1 \%$ of DMSO as the solvent control. Then, the chamber was placed into a humidified incubator. After $8 \mathrm{~h}$, assays were stopped by removal of the medium from the upper wells and careful removal of the filters. Filters were fixed with methanol by brief submersion and were subsequently wiped on the cells on the upper side using the Q-tip. Filters were stained with $20 \%$ Giemsa solution (Sigma Chemical) for the light microscope or 4'-6-diamidino-2-phenylindole for the fluorescent microscopy-based high content screening system (Cellomics). Evaluation of completed transmigration was performed under the microscope, and random fields were scanned (four fields per filter) for the presence of cells at the lower membrane side only.

\section{Cancer Cell Invasion Assay}

The cancer cell invasive ability with or without indicated treatment was examined by membrane transwell culture system as described previously (7). Briefly, Transwell membrane (8- $\mu \mathrm{m}$ pore size, $6.5-\mathrm{mm}$ diameter; Corning Costar Corporation) coated with Matrigel $(2.5 \mathrm{mg} / \mathrm{mL}$; BD Biosciences Discovery Labware) was used for invasion assay. Cells were trypsinized, centrifuged, and resuspended at $10^{7}$ cells $/ \mathrm{mL}$ in DMEM. Cells were seeded onto the upper wells of precoated transwells, $2 \times 10^{4}$ cells per well. Lower wells of the transwells contained the same medium with $10 \%$ FBS. After $18 \mathrm{~h}$ of incubation, the cells on the upper well and the membranes coated with Matrigel were swabbed with a Q-tip, fixed with methanol, and stained with $20 \%$ Giemsa solution (Sigma Chemical). The cells that were attached to the lower surface of the polycarbonate filter were counted under a light microscope (magnification, $\times 200$ ). The experiments were performed thrice in triplicate.

\section{In vivo Animal Studies}

We perform the in vivo metastasis assay in mice according to the protocols approved by the National Yang-Ming University Animal Care and Use Committee. The CL1-5 cells were pretreated with scramble or HLJ1 siRNA for $24 \mathrm{~h}$ and recalculate the cell survival and cell number by trypan blue; finally, $5 \times 10^{5}$ live CL1-5 cells in $100 \mu \mathrm{L}$ PBS were injected into the tail vein of 8-wk-old severe combined immunodeficient (SCID) mice (supplied by the animal center in the College of Medicine, National Taiwan University). To examine the effects of curcumin on the cancer colonization in lung, the mice with scramble or HLJ1 siRNA-treated CL1-5 cells were randomly grouped into curcumin-treated or untreated groups. Curcumin was suspended in the Propylene Glycol (J.T.Baker) for p.o. administration and dosed p.o. once daily at $1 \mathrm{~g} / \mathrm{kg}$ for $5 \mathrm{wk}$ of treatment. After $5 \mathrm{wk}$, the mice were sacrificed and analyzed for the lung colonization. The lungs (or other organs) were rinsed with PBS and then placed in a beaker containing Bouin's solution. After $24 \mathrm{~h}$, the lungs were rinsed in water to remove excess Bouin's solution and the tumor colonies were counted under a dissecting microscope and double confirmed under a microscope in histology by H\&E staining and human vimentin immunostaining.

\section{Real-time Quantitative Reverse Transcription-PCR}

The expression level of $H L J I$ was detected with real-time PCR on ABI prism 7900 sequence detection system (Applied Biosystems). The HLJ1 primers are as follows: forward primer QHLJI-F, 5'-CCAGCAGACATTGTTTTTATCATT- $3^{\prime}$; and reverse primer QHLJ1-R, 5'-CCATCCAGTGTTGGTACATTAATT-3'. TATA-box binding protein (TBP) was used as the internal control (Genbank X54993). The primers and probe used for quantitative reverse transcription-PCR (RT-PCR) of TBP mRNA were as described previously $(23,24)$. The relative expression level of $H L J 1$ compared with that of $T B P$ was defined as $-\triangle \mathrm{CT}=-\left[\mathrm{CT}_{\mathrm{HLJ1}}-\mathrm{CT}_{\mathrm{TBP}}\right]$. The $H L J 1 \mathrm{mRNA} / T B P$ mRNA ratio was calculated as $2^{-\Delta \mathrm{CT}}, K$, in which $K$ is a constant. Experiments were performed thrice in triplicate.

\section{Western Blot, Immunofluorescent Staining, and Flow}

\section{Cytometry}

Western blot and immunohistochemistry were used to examine the protein expression levels of HLJ1, c-Jun, JunB, JunD, Fra-1, Fra-2, and E-cadherin before and after curcumin treatment, whereas, the flow cytometry was used to confirm the E-cadherin expression in curcumintreated cells. The detailed procedures were as described previously (18). The primary antibodies for c-Jun, JunB, JunD, c-Fos, Fos-B, Fral, and Fra2 were purchased from Santa Cruz Biotechnology, Inc., E-cadherin was purchased from signaling transduction (BD Biosciences), and primary antibody for HLJ1 was made in house (16). Monoclonal mouse anti- $\alpha$ tubulin (1:500; Calbiochem) was used for loading control. The membranes were then washed thrice with TBST, followed by incubation with horseradish peroxidase-conjugated secondary antibody $(1: 4,000)$ in TBST $/ 2 \%$ skim milk. Bound antibody was detected using the Enhanced Chemiluminescence System. Chemiluminescent signals were captured using the Fujifilm LAS 3000 system (Fujifilm). All experiments were performed at least thrice in duplicate.

FITC-conjugated second antibody (Biotech, Inc.) was used for immunofluorescent staining. Propidium iodide was used as counter staining for cell nuclei. The stained cells were then examined by a confocal laser scanning microscope (Clsi; Nikon) at $\times 400$ magnifications. The cells stained with E-cadherin antibody, and FITC-conjugated second antibody were analyzed by flow cytometry (Beckman-Coulter; EPICS-XL). Experiments were performed thrice in triplicate. 


\section{HLII Promoter and Enhancer and Luciferase Reporter Gene}

\section{Constructs}

To clone the putative promoter and/or enhancer region of the HLJI gene, a PCR-based method was used and specific primers were designed from the
5 '-end of the known HLJ1 promoter sequence from our previous study (25) and from the bioinformatic search in Genbank. The amplified DNA fragment of 2,302 bp was cloned into the promoterless pGL3-Basic vector (Promega) to construct pGL3-FRER' as from the previous study (25).

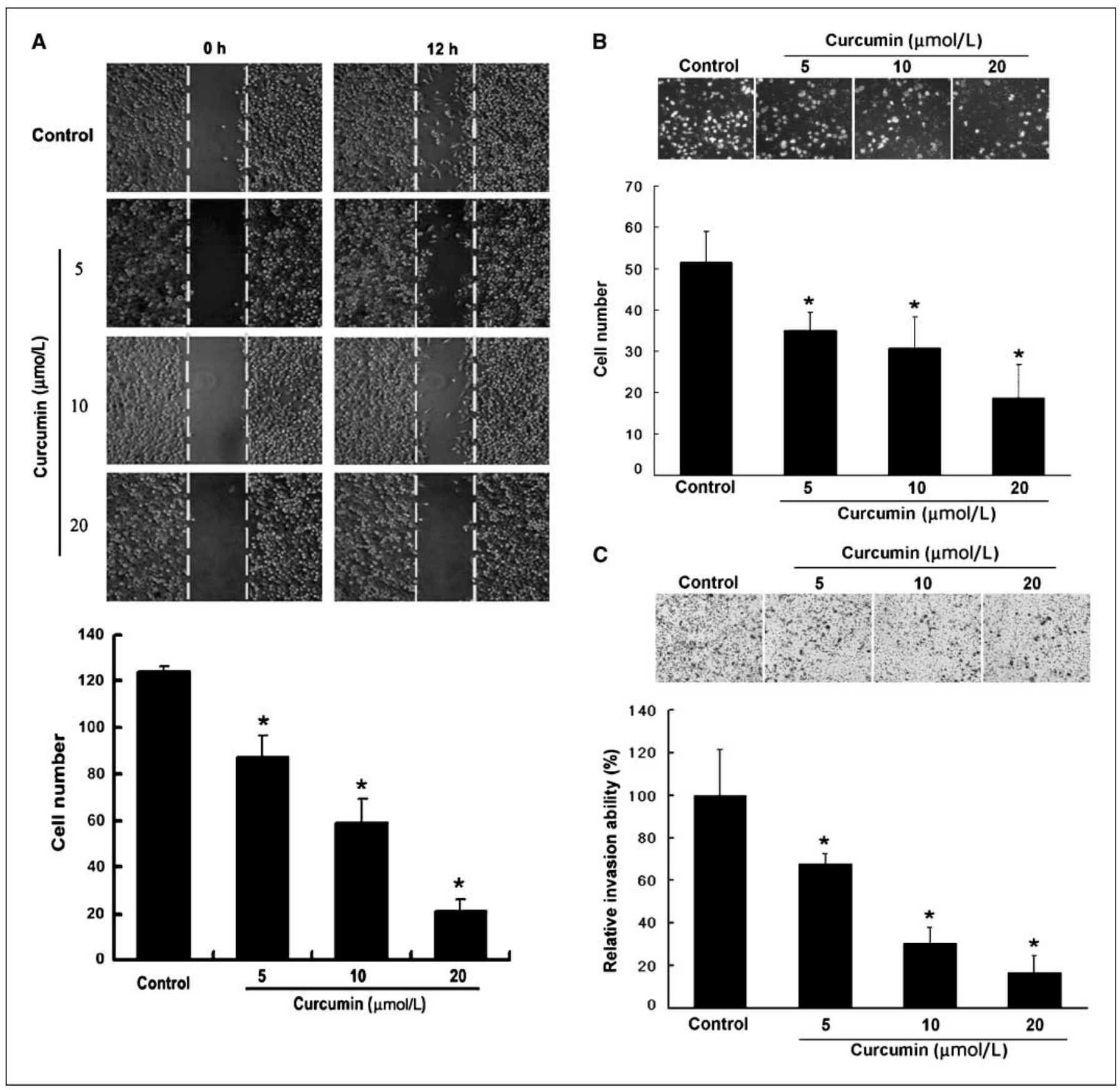

Figure 1. Curcumin inhibits cancer cell migration and invasion in CL1-5 cells. $A$, the wound-healing assay for evaluating the inhibitory effects of curcumin on CL1-5 cell migration. Confluent monolayers of CL1-5 cells were scarred, and repair was monitored microscopically after $12 \mathrm{~h}$ of treatment with curcumin (5-20 $\mu$ mol/L). The cells migrating into the wound area were counted based on the dash line as time zero. The representative photographs showed the same area at time zero and after $12 \mathrm{~h}$ of incubation with or without curcumin. Columns, mean $(n=3)$; bars, SD. ${ }^{*}, P<0.05$, statistically significantly compared with the vehicle-treated control. These results are representative of three independent experiments. $B$, the Transwell migration assay showed the inhibitory effects of curcumin on CL1-5 cell migration. After $8 \mathrm{~h}$ of incubation with or without the indicated concentration of curcumin, cells that migrate to the lower chamber were fixed, stained, and counted using light microscopy or flurescent microscopy-based high content screening system, as describe in Materials and Methods. Random fields were scanned (four fields per filter of the well) for the presence of cells on the lower side of the membrane. Columns, mean of the migrated cells from three independent experiments and three wells per experiment; bars, SD. * $P<0.05$, statistically significant. $C$, the effect of curcumin treatment on cell invasion was determined using the Matrigel Invasion Assay System. CL1-5 cells in serum-free medium with or without curcumin were seeded into the upper chamber of the system. The bottom well was filled with complete medium. After $16 \mathrm{~h}$ of incubation, the cells that had invaded through the Matrigel membrane were stained with $20 \%$ Giemsa solution and counted under a light microscope (magnification, $\times 200$ ). The experiments were performed thrice in triplicate. Columns, mean of invasive cell number from three independent experiments; bars, SD. ${ }^{*}, P<0.05$, statistically significant. 
According to our previous works, varying lengths of the $5^{\prime}$-flanking region of the HLJ1 gene for luciferase assays were generated $(17,25)$. The pGL3Control, a positive control plasmid, was also obtained from Promega. The putative enhancer $(-2,125$ to $-1,039)$ element and its various deletion mutants were generated by PCR and subcloned into pGL3-promoter vector as our previous study described (25). This vector contains the luciferase gene driven by SV40 promoter. The same cloning strategy was used to generate the minimal enhancer construct pGL3-p-Emi. For sitedirected mutagenesis assay, the pGL3-p-Emi construct served as a template for the generation of mutations in the SP1 and AP-1 binding sites. All mutant constructs were prepared by PCR using appropriate primers containing the mutations. The composition of all of the constructs was confirmed by restriction endonuclease digestion and DNA sequencing.

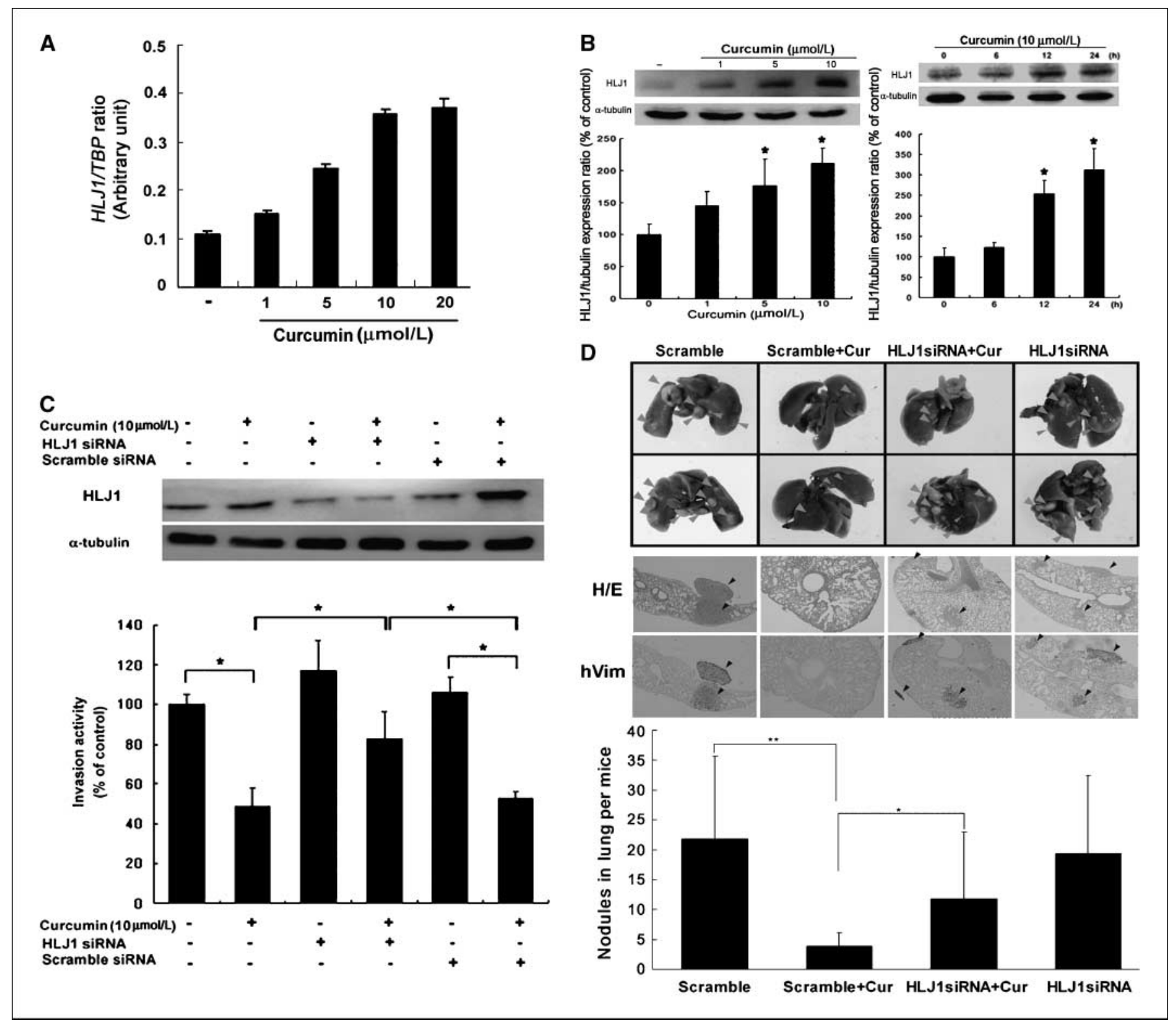

Figure 2. Curcumin (cur) induces HLJ1 expression and inhibits cancer cell migration and invasion. A, real-time quantitative RT-PCR reveals that HLJ1 mRNA expression was induced by curcumin in a concentration-dependent manner $(1-20 \mu \mathrm{mol} / \mathrm{L})$ after $24 \mathrm{~h}$ incubation. $B$, concentration-dependent and time coursedependent curcumin-induced HLJ1 expression at the protein level were confirmed by Western blotting analysis. The results indicated that the protein level of HLJ1 was significantly increased after curcumin $(10 \mu \mathrm{mol} / \mathrm{L})$ treatment for 12 to $24 \mathrm{~h}$. The expression levels were qualified by densitometer and calculated relative to the expression level of $\alpha$-tubulin (as the internal control) and are shown as the mean expression levels from three independent experiments; columns, mean $(n=3$ ); bars, SD. ${ }^{*}, P<0.05$, statistically significantly compared with vehicle-treated control. $C$, Western blotting showed the HLJ1 expression levels of HLJ1 siRNA or scrambled siRNA-transfected (control) CL1-5 cells with or without curcumin treatment. Data are representative of at least three independent experiments with $\alpha$-tubulin used as the internal control. HLJ1 protein expression was reduced by HLJ1 siRNA both in the base level and curcumin-treated cells (lane 3 and 4), whereas there was no effect within the scrambled siRNA control group (lane 5 and 6). Bottom, the HLJ1 knockdown specifically reduced the anti-invasive activity of curcumin. Cells transfected with control or HLJ1 siRNA were treated with or without curcumin and then tested in invasion assays across a Transwell membrane coated with Matrigel. Columns, mean derived from three separate experiments done in quadruplicate; bars, SD. ${ }^{*}, P<0.05$. $D$, the tail vein assay of cancer metastasis was used to examine the role of HLJ1 in the antimetastatic effects of curcumin in vivo. CL1-5 cells transfected with scrambled RNA or HLJ1 siRNA were injected into tail vein of the SCID mice $\left(5 \times 10^{5}\right.$ cells per mice, at least 6 mice for each group). The curcumin-treated groups were orally treated with curcumin ( $\left.1 \mathrm{~g} / \mathrm{kg} / \mathrm{day}\right)$. Five weeks later, the numbers of pulmonary tumor nodules were examined by staining with Bouin's solution. The tissue sections were stained with $\mathrm{H} \& \mathrm{E}$ and immunostaining with human vimentin. Columns, mean $(n>6)$; bars, SD. ${ }^{*}, P<0.05$, statistically significant compared with vehicle-treated control; ${ }^{*}, P<0.05$, statistically significant compared with the scramble control. 


\section{Transfection and Luciferase Reporter Assays}

All transfections were performed in triplicate in 6-well plates, and the detail protocol was described in previous studies $(18,25)$. In brief, CL1-5 cells $\left(\sim 2 \times 10^{5}\right.$ cells per well $)$ were seeded for $24 \mathrm{~h}$ prior to transfection. Plasmids were transfected into cells using Lipofectamine 2000 reagent according to the manufacturer's instructions (Invitrogen). The HLJI promoter and enhancer luciferase reporter constructs (25), along with the control plasmid, was cotransfected with a $\beta$-galactosidase construct, pSV- $\beta$-Gal (Promega). The ratio of the DNA amounts for luciferase reporter constructs versus $\beta$ galactosidase construct was 3:1. The cells were incubated in transfection mixture for $4 \mathrm{~h}$ and then harvested after $44 \mathrm{~h}$ in culture. An aliquot of cell lysate $(10-25 \mu \mathrm{L})$ was used to assay luciferase activity using a luciferase assay kit (Tropix, Inc.). Another aliquot $(10-25 \mu \mathrm{L})$ was used to measure $\beta$ galactosidase activity using the Galacto-Light chemiluminescent assay kit (Tropix, Inc.). Luminescence was measured with a Victor2 1420 Multilabel Counter (Wallac). Transfection efficiency was normalized with $\beta$-gal activity. Each experiment was repeated at least thrice.

\section{Actin Staining}

Cells were washed twice with PBS and fixed in a 3.7\% formaldehyde-PBS solution for $10 \mathrm{~min}$ at room temperature. After two additional washes with PBS, cells were permeabilized with a solution of $0.1 \%$ Triton X-100 in PBS for 3 to $5 \mathrm{~min}$ and washed again with PBS. Phalloidin-tetramethylrhodamine isothiocyanate $(0.2 \mu \mathrm{g} / \mathrm{mL})$ and Alexa Fluor 488 DNase I conjugate $(9 \mu \mathrm{g} / \mathrm{mL})$ were used to localize filamentous actin (F-actin) and G-actin, respectively, as described by Cramer and colleagues (26). Fluorescent dyes were diluted on blocking solution ( $1 \%$ bovine serum albumin and $0.025 \%$ saponin in PBS) and added to coverslips for $40 \mathrm{~min}$ at room temperature. After three washes with PBS, coverslips were mounted on a microscopy slide with mounting media (Vector Laboratories). Time of image acquisition and image intensity gain were optimally adjusted and kept constant for all experiments. F-actin to G-actin fluorescence ratio was quantified using fields containing $>30$ cells imaged with an inverted fluorescence microscope (Eclipse TE2000; Nikon) and a 12-bit resolution cooled charge-coupled device camera (Orca; Hamamatsu Photonics) at $\times 10$ magnification as previously report (27). F-actin cytoskeleton imaging was performed with a confocal laser scanning microscope (Clsi; Nikon) at $\times 400$ magnifications.

\section{Statistical Analysis}

All experiments were performed in triplicate and analyzed by ANOVA (Excel; Microsoft) for significant differences. $P$ values of $<0.05$ were considered statistically significant. Where appropriate, the data are presented as the mean \pm SD.

\section{Results}

Curcumin inhibits cancer cell migration and invasion. CL1-5 is a highly invasive cancer cell line both in vitro and in vivo (22). Due to the fact that curcumin could induce cell apoptosis and reduce cell viability as the concentrations of curcumin over $20 \mu \mathrm{mol} / \mathrm{L}$ (the $\mathrm{IC}_{50}$ is $33.2 \pm 3.7 \mu \mathrm{mol} / \mathrm{L}$ in CL1-5 cells; ref. 7 ), the effects of curcumin on migration and invasion abilities of CL1-5 cells were performed at the concentration range below $20 \mu \mathrm{mol} / \mathrm{L}$ and determined by the wound-healing assay, the Transwell migration model, and the Matrigel-based Transwell invasion assay. Concentration dependently, curcumin $(5-20 \mu \mathrm{mol} / \mathrm{L})$ was able to significantly inhibit CL1-5 cancer cell migration, and this effect was consistent across both the wound-healing and transwell migration models (Fig. $1 A$ and $B$ ). In addition, the Matrigel-based transwell assay indicated that curcumin was able to inhibit cell invasion (Fig. $1 C$ ). Similar results whereby curcumin inhibited cell migration and invasion were confirmed for another invasive lung cancer cell line, A549 (data not shown), indicating that this observation would seem to be neither cell specific nor a coincidence.

Suppression of cancer cell invasion and metastasis by curcumin is associated with up-regulation of HLJ1. To elucidate the anti-invasion and antimetastasis mechanisms of curcumin, curcumin-regulated differentially expressed genes in CL1-5 cells were profiled in our previous study (7), and some of these genes are highly correlated with the invasive ability of cancer cells (8). Herein, one curcumin-regulated tumor suppressor and invasion suppressor gene HLJI (17) is examined. As shown in Fig. 2, we confirmed that curcumin was able to increase both the mRNA and protein expression levels of HLJ1 in CL1-5 cells in a concentrationand time-dependent manner (Fig. $2 A-B$ ).

To evaluate the importance of HLJ1 in the anti-invasive effect of curcumin in CL1-5 cells, a specific siRNA for HLJ1 was used to knockdown HLJ1 expression in curcumin-treated cells. We found that HLJ1 expression decreased after 24 hours of $20 \mathrm{nmol} / \mathrm{L} \mathrm{HLJ1}$ siRNA treatment; furthermore, the effect of curcumin-induced HLJ1 expression was also reduced by $67 \% \pm 7.2 \%$ compared with curcumin-treated group by HLJ1 siRNA $(P<0.05$; Fig. $2 C)$. In the same experiment, the anti-invasive effect of curcumin was reversed by pretreated with HLJ1 siRNA (Fig. $2 C$ ). These results showed that $51.4 \% \pm 8.7 \%$ of cancer cell invasion could be inhibited by curcumin and that this effect was reduced to $20.1 \% \pm 12.6 \%$ if cells were preincubated with HLJ1 siRNA before curcumin treatment. On the other hand, the scrambled siRNA control showed no difference compared with the control group.

To examine the role of HLJ1 in the antimetastatic effects of curcumin in vivo, the i.v. experimental lung metastasis model in SCID mice was used. CL1-5 cells transfected with scrambled siRNA (mock) or HLJ1 siRNA were counted $\left(5 \times 10^{5}\right.$ cells) and injected into tail vein of the SCID mice. These mice were then treated with or without curcumin (p.o., $1 \mathrm{~g} / \mathrm{kg} /$ day). After 5 weeks, the numbers of colonized pulmonary tumor nodules were counted. Most of the pulmonary tumor colonies in the mice were found near or on the surface of the lungs (Fig. 2D). The data showed that injection with mock cancer cells could result $21.80 \pm 13.84$ pulmonary colonized tumor nodule formation per mice. The curcumin-treated group showed a significantly reduced number of the colonized tumor nodules in the lungs compared with the mock control group (3.89 \pm 2.28 nodules per mice; $P<0.05$ ). The knockdown HLJ1 was able to attenuate the antimetastatic effects of curcumin in vivo as shown by the fact that the HLJ1 siRNA-transfected plus curcumin-treated group showed many nodules (11.78 nodules per mice) compared with the scrambled siRNA plus curcumin-treated group (3.89 nodules per mice). These results indicated that HLJ1 would seem to play a role in the antimetastasis effects of curcumin.

The AP-1 site within the HLJI enhancer and the JNK/JunD signaling pathway are responsible for HLJ1 up-regulation by curcumin. We have previously identified that the YY1 and AP-1 binding sites in the $H L J 1$ promoter and enhancer regions play a major role in $H L J 1$ transcriptional regulation $(18,25)$. To study whether curcumin could regulate HLJ1 expression through the promoter and/or enhance regions of $H L J 1$, several constructs with deletions or mutations were used and have been previously described in detail (25). The full length of the HLJ1 promoter with enhancer construct (PGL3-FRER') was used to show that curcumin could concentration-dependently induce luciferase activity (Fig. $3 A$ ), whereas curcumin has less effect on the promoter only construct (PGL3-F2RER'). Interestingly, curcumin was able to significantly increase the luciferase activity of the minimum enhancer region (Emi-F/R; data not shown), which contains the AP-1 and SP-1 binding sites. Site-directed mutagenesis indicated that the AP-1 site $(-1,457$ to $-1,451)$ and not the SP-1 site was essential for the curcumin-regulated $H L J 1$ enhancer region activity (Fig. $3 B$ ). There 
are several protein components that make up the AP-1 complex, including c-Jun, c-Fos, JunD, JunB, Fra-1, and Fra-2. On studying the effects of curcumin on the AP-1 subunit family, we found that only JunD was able to be significantly induced by curcumin in CL1-5 cells (Fig. $3 C$ ). In contrast to c-jun, which was shown to be slightly downregulated, JunB shows an ascending trend, whereas Fra-1, Fra-2, and c-Fos are not affected significantly by curcumin over the concentration range used (1-10 $\mu \mathrm{mol} / \mathrm{L}$; Fig. $3 C$ ). Furthermore, time course studies showed that the dynamic effects of curcumin during the induction of JunD expression occurred after 2 hours of incubation at the mRNA level and after 4 hours at protein level. This is just a little earlier than the induction of HLJ1 expression in curcumin-treated cells (Fig. $3 D$ ).

To confirm the role of JunD in curcumin-induced HLJ1 expression, JunD siRNA was applied to curcumin-treated CL1-5 cells to knock down JunD expression. The Fig. $4 A$ showed that
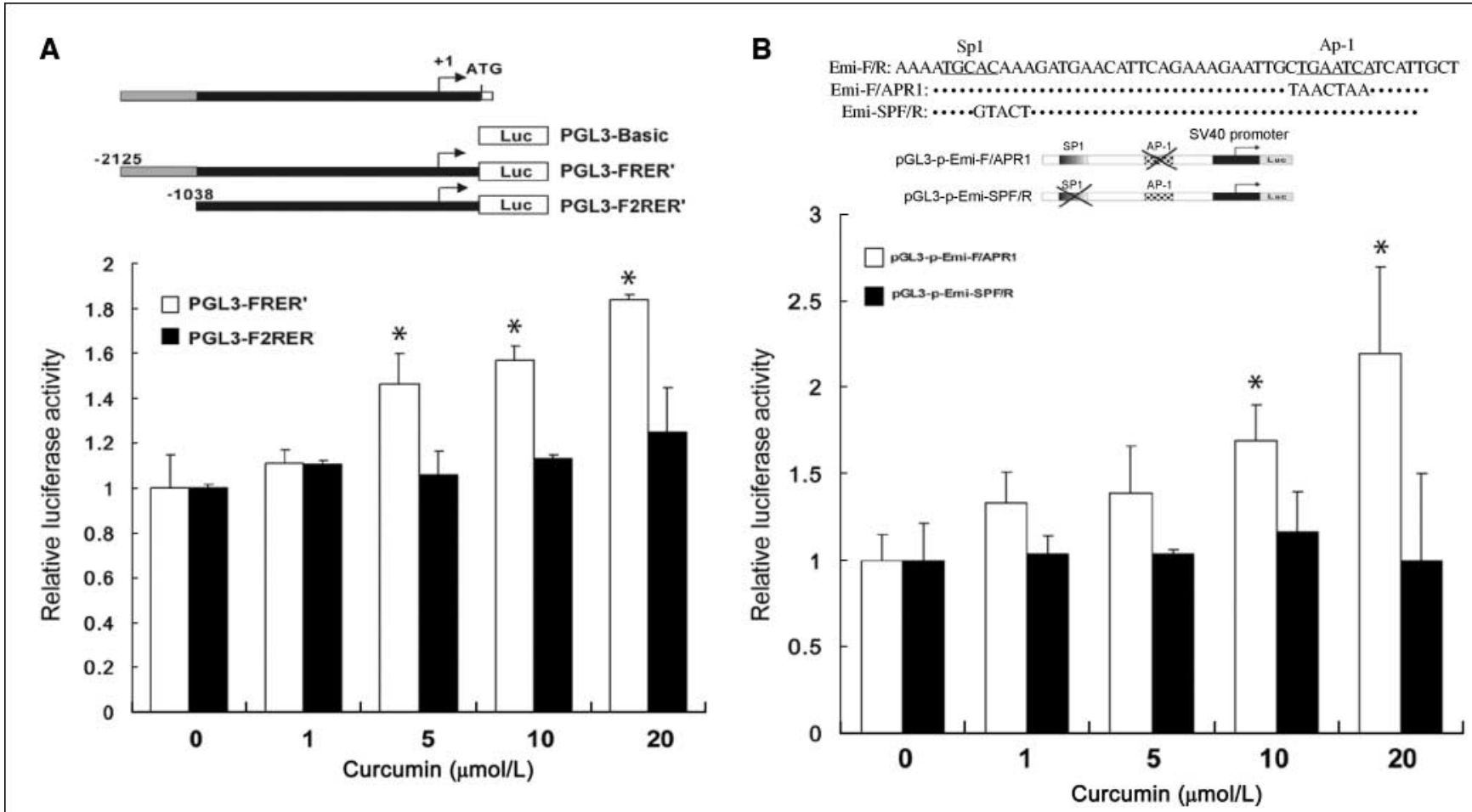

C

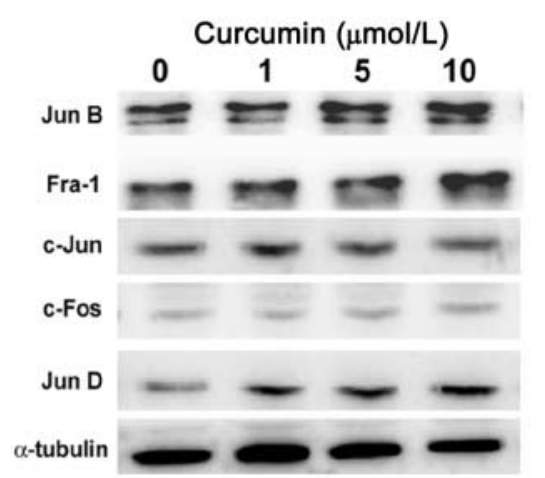

D
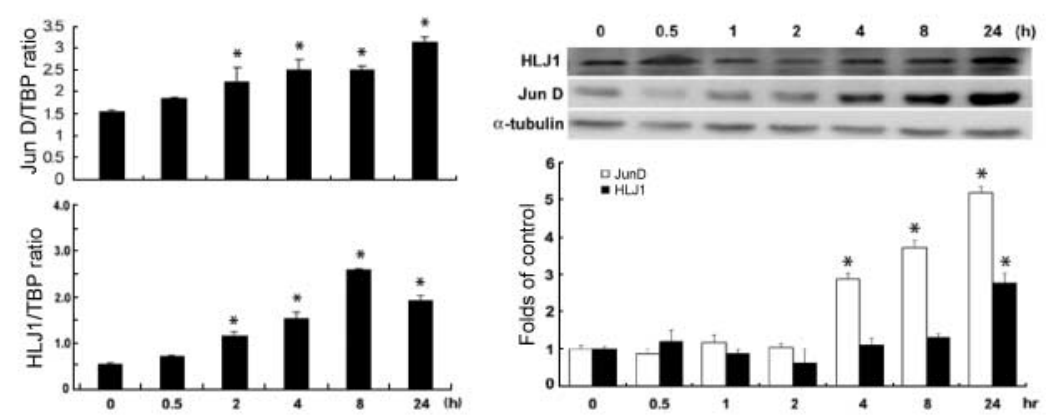

Figure 3. The regulation effects of curcumin on the HLJ1 promoter and enhancer. A, relative luciferase activities of pGL3-FRER' (containing the potential enhancer element) and pGL3-F2RER' (containing full-length and basal promoter) were determined in CL1-5 cells treated with or without curcumin (1-20 $\mu$ mol/L). The results were correlated with the luciferase activity from cotransfected pSV- $\beta$-Gal cells and expressed as relative luciferase activity. Columns, mean ( $n=3$ ); bars, SD.

${ }^{*}, P<0.05$, statistically significant compared with vehicle-treated control. These results are representative of three independent experiments. $B$, the mutation analysis of HLJ1 minimum enhancer activity indicated that the AP-1 site is critical for curcumin-induced HLJ1 enhancer activity. The mutant derivatives of the enhancer region in which either the motif was substituted or a combination of motif mutations was fused to the pGL3-promoter vector. pGL3-p-Emi-F/APR1, the constructs of site-directed mutagenesis of the AP-1 site; pGL3-p-Emi-SPF/R, the constructs of site-directed mutagenesis of the SP-1 site. The results were correlated with luciferase activity from cotransfected pSV- $\beta$-Gal and expressed as relative luciferase activity. Columns, mean $(n=3)$; bars, SD. *, $P<0.05$, statistically significant compared with vehicle-treated control. These results are representative of three independent experiments. $C$, Western blotting analysis showing that the expression of the components of AP-1 (c-Jun, c-Fos, JunD, JunB, Fra-1, and Fra-2) are regulated by curcumin (1-10 $\mu \mathrm{mol} / \mathrm{L}$ ) and were detected using the indicated antibodies for JunB,

Fra-1, c-Jun, c-Fos, and JunD. D, real-time quantitative RT-PCR and Western blotting reveal that junD and HLJ1 expression were induced by curcumin in mRNA and protein levels at the indicated times $(0,0.5,2,4,8$, and $24 \mathrm{~h})$ of incubation. Left, the mRNA dynamic changes after curcumin treatment. Columns, mean $(n=3) ;$ bars, SD. *, $P<0.05$, statistically significant compared with vehicle-treated control. These results are representative of three independent experiments. Right, Western blotting analysis indicated that JunD and HLJ1 protein expression were induced by curcumin in a time-dependent manner. Columns, mean $(n=3)$; bars, SD. *, $P<0.05$, statistically significant compared with vehicle-treated control. These results are representative of three independent experiments. 


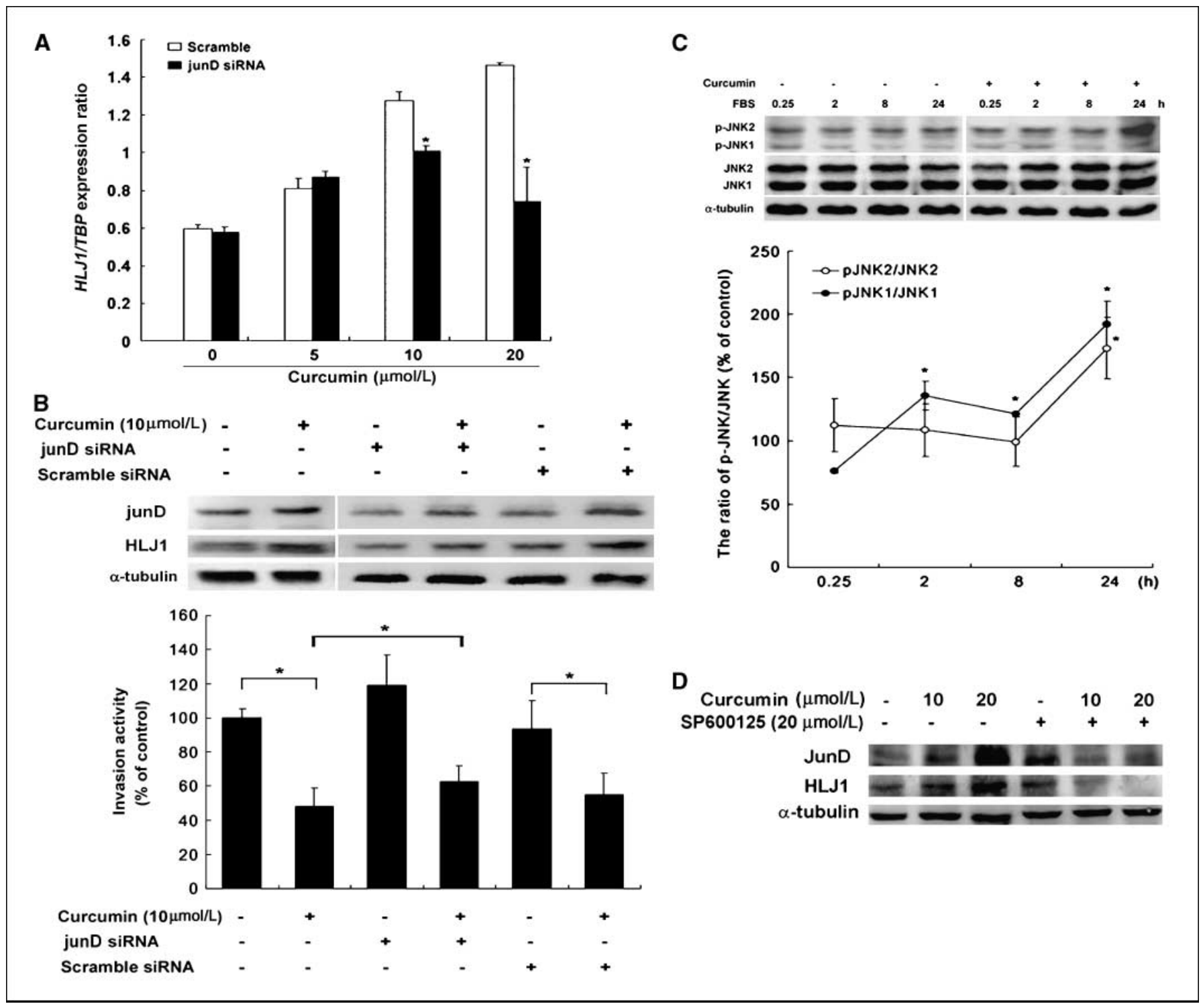

Figure 4. JunD knockdown specifically reduces curcumin-induced HLJ1 expression and the anti-invasive activity of curcumin. $A$, real-time quantitative RT-PCR reveals that curcumin-induced HLJ1 mRNA expression was inhibited in CL1-5 transfected with JunD siRNA compared with the scrambled siRNA control. Columns, means from three separate experiments; bars, SD. *, $P<0.05$. B, CL1-5 transfected with JunD siRNA or the scrambled siRNA control were treated with or without curcumin and then analyzed by Western blotting. HLJ1 protein expression was reduced by JunD siRNA both at base level and in the curcumin-treated cells (lane 3 and 4), whereas no effect was detected in the scrambled siRNA control groups (lane 5 and 6 ). The sample preparations of the cells transfected with control or HLJ1 siRNA with or without curcumin were tested in invasion assays across a Transwell membrane coated with Matrigel in the bottom panel. Columns, mean derived from three separate experiments done in quadruplicate; bars, SD. * $P<0.05$. $C$, the effects of curcumin on JNK activation at the indicated time periods $(0.25,2,8$, and $24 \mathrm{~h})$. After stimulating with 10\% FBS, the JNK1, JNK2, p-JNK1, and p-JNK2 were examined by Western blotting with JNK and phosphor-JNK specific antibodies. The ratios of $p$-JNK1/JNK1 and p-JNK2/JNK2 were performed as below by densitometer. Columns, mean; bars, SD. ${ }^{*}, P<0.05$, statistically significantly compared with vehicle-treated control. These results are representative of three independent experiments. $D$, curcumin-induced JunD and HLJ1 expression through JNK activation. Western blotting shows that SP600125, a JNK inhibitor, is able to inhibit curcumin-induced JunD and HLJ1 expression. These results are representative of three independent experiments.

pretreatment with JunD siRNA was able to reduce curcumininduced $H L J 1$ mRNA expression (Fig. 4A). This effect was confirmed at the protein levels for JunD and HLJ1 by Western blot analysis as shown in Fig. $4 B$. In the same preparation, the anti-invasive effect of curcumin was reduced by pretreatment with JunD siRNA (Fig. 4B). To further investigate the regulation of curcumin on the JunD upstream modulator, c-Jun- $\mathrm{NH}_{2}$-kinase (JNK) and phosphorylation of JNK were examined (Fig. $4 C$ ). The data showed that two isoforms of JNK, JNK1, and JNK2 were both expressed in CL1-5 cells and were not affected by curcumin treatment. The phospho-form of JNK1 and JNK2, p-JNK1 and p-JNK2, were significantly induced by curcumin with dynamic changes (Fig. $4 C$ ). This contrasts with the effect of the JNK inhibitor (SP600125), which was able to reduce the effects of curcumin-induced JunD and HLJ1 expression in CL1-5 cells (Fig. $4 D$ ). These results showed that JNK phosphorylation and JunD would seem to be involved in the curcumin-induced HLJ1 signaling pathway in CL1-5 cells.

Curcumin up-regulates HLJ1 and E-cadherin expression, suppresses filopodia formation, and inhibits cancer cell invasion. The question remains as to how curcumin-induced HLJ1 expression is able to affect cancer cell invasion. Our previous study suggested that HLJ1 was able to inhibit cell invasion through 
the induction of E-cadherin expression (18), and other evidence has suggested that these DnaJ-like proteins might interact with actin, tubulin, or various intermediate filaments to restrict cellular activity (28). Immunostaining of curcumin-treated CL1-5 cells showed that there was up-regulation and localization of E-cadherin into the cell-cell junctions together with a mesenchymal-epithelial phenotype transition (Fig. $5 A$ ). Western blot and flow cytometry analysis confirmed that the E-cadherin protein levels are upregulated by curcumin in a concentration-dependent manner (5-20 $\mu \mathrm{mol} / \mathrm{L}$; Fig. $5 B$ and $C$ ). HLJ1 siRNA was able to specifically knockdown HLJ1 protein levels and this significantly diminished curcumin-induced E-cadherin expression $(P<0.05$; Fig. $5 D)$.

Because HLJ1, such as other DnaJ family members, might modulate cell invasion through regulating the kinetics of actin, tubulin, or various other intermediate filaments (28), we examined the effects of curcumin on actin polymerization. As shown in Fig. $6 A$, curcumin did not significantly affect the total amount of actin. However, the F-actin (polymer)/G-actin (monomer) ratio was significantly decreased by curcumin treatment in a concentration-dependent manner (Fig. 6B). Figure $6 C$ shows that curcumin also decreased cell membrane filopodia protrusions and induced an abnormal aggregation of actins in cytosol of the curcumin-treated cells (Fig. 6C).

\section{Discussion}

Curcumin has long been known to act as a therapeutic or preventive agent for several major human cancers by regulating a variety of antitumor signaling pathways $(29,30)$. In this study, we have confirmed that curcumin can inhibit the invasion and metastasis of lung cancer cells in vitro and in vivo. We found that curcumin can suppress cancer cell invasion and metastasis through the up-regulation of the tumor suppressor HLJ1. Curcumin is able to transcriptionally activate HLJ1 expression through the JNK/JunD pathway. Activation of HLJ1 by curcumin further leads to upregulation of E-cadherin, and this inhibits cancer cell invasion and metastasis. Our results strengthen the potential of curcumin as a multitarget drug in anticancer therapy $(1,31,32)$.

The emerging concept of integrating gene expression profiles after small molecule treatment of specific diseases has been suggested to be an effective strategy for the identification the new drug development targets (33). We have previously generated two cDNA microarray data sets: namely the cancer invasion/metastasis associated gene data set obtained from cell lines with different invasive abilities (CL1-0 to CL1-5; ref. 8) and the curcuminregulated gene expression signature data set (7). By combining and sorting the curcumin-regulated genes and the invasion/metastasisassociated genes from these two data sets, the tumor suppressor HLJ1 was one of the selected candidate targets for control of metastasis and invasion. This was further confirmed in this study, which showed that HLJ1 is a potential new treatment target for the control cancer cell invasion by curcumin. These results are consistent with our previous study and support the hypothesis that the tumor suppressor HLJ1 is an important target for antiinvasion, antimetastasis, and antiangiogenesis in cancer therapy $(17,19)$. Our findings help to shed some light on the development of new drugs such as curcumin analogues that may inhibit cancer invasion and metastasis by targeting HLJ1.

A previous study showed HLJ1 to be regulated by AP-1 through the enhancer region of $H L J 1 \quad(18,25)$. The AP-1 transcription factor complex, composed mainly of Jun-Jun and Jun-Fos protein dimer,

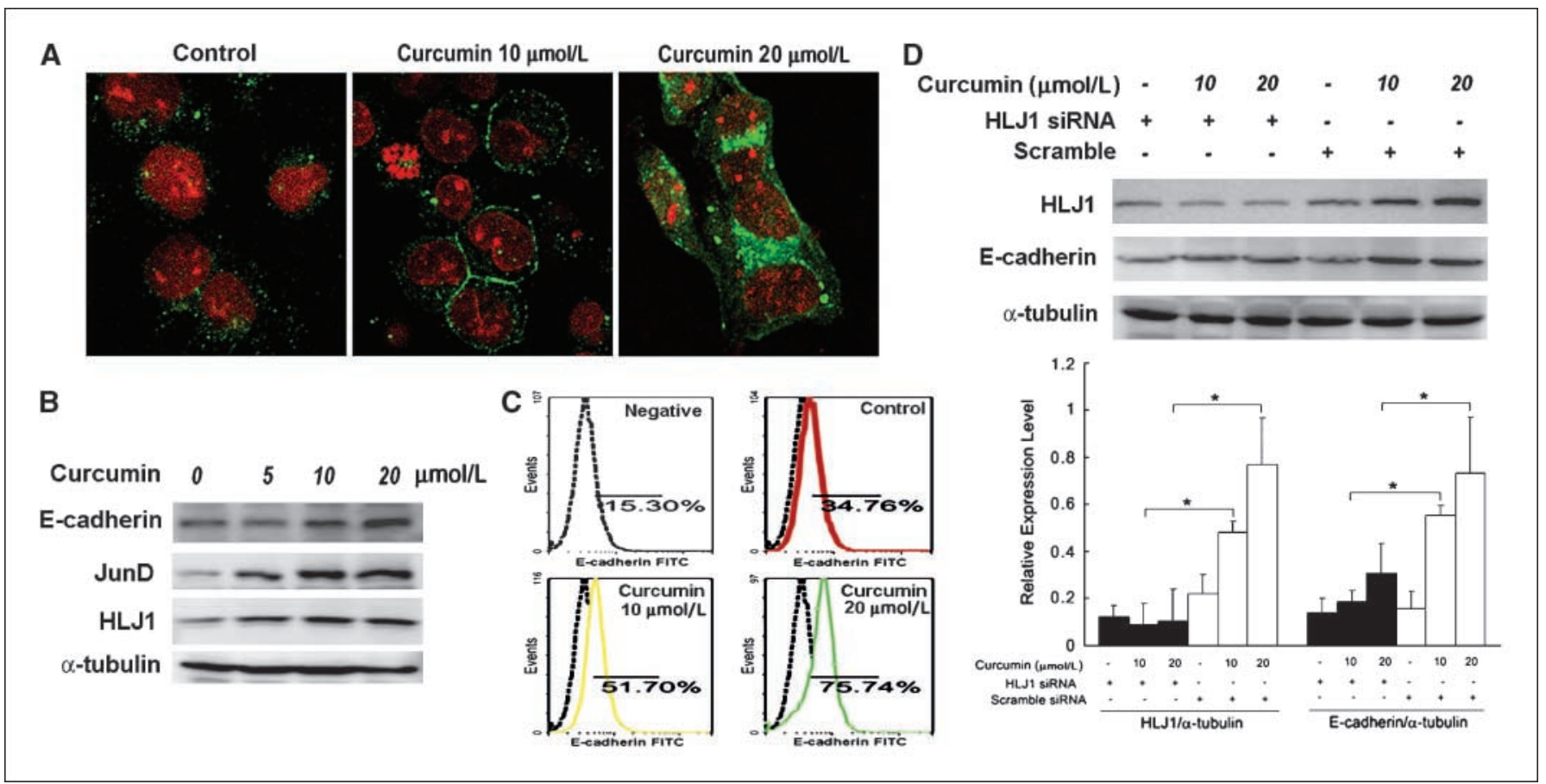

Figure 5. Curcumin induces E-cadherin expression through HLJ1 induction. $A$, immunostaining shows the up-regulation and localization of E-cadherin in curcumin-treated cells. The E-cadherin shows strong staining at cell-cell junction in curcumin-treated cells. Original magnification, $\times 400$. $B$, immunoblotting shows the

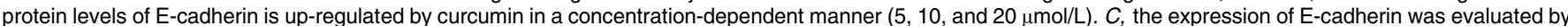

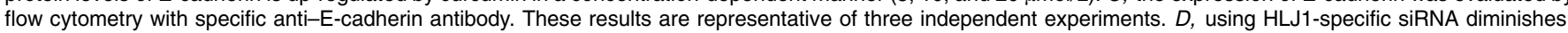
curcumin-induced E-cadherin expression compared with the scrambled siRNA control assessed by Western blotting. The protein expression levels of HLJ1 and

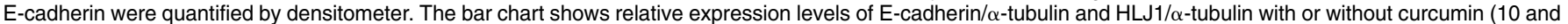
$20 \mu \mathrm{mol} / \mathrm{L})$ treatment in HLJ1 siRNA or scrambled siRNA-transfected CL1-5 cells $(n=3) .{ }^{*}, P<0.05$. 
A

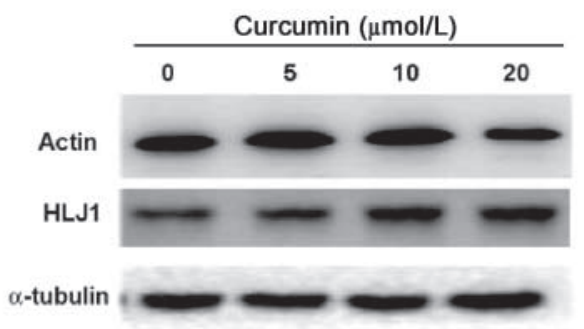

C

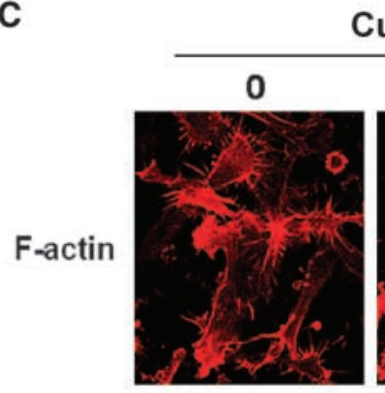

Curcumin $(\mu \mathrm{mol} / \mathrm{L})$
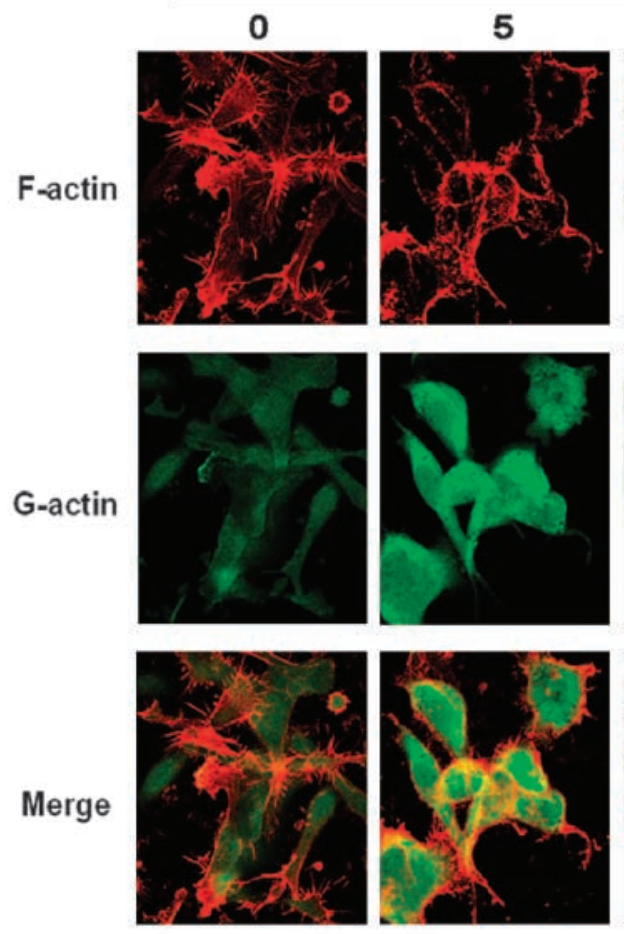

B

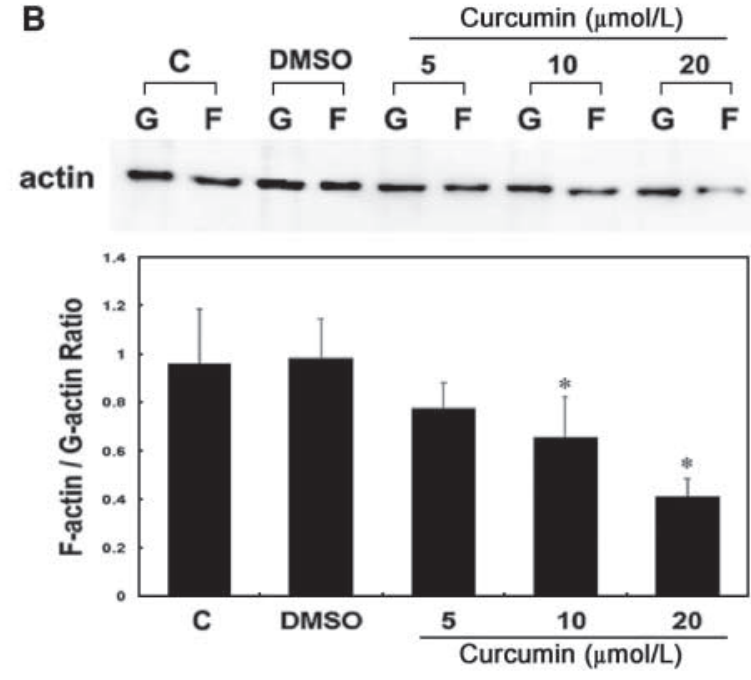

D

\section{0}
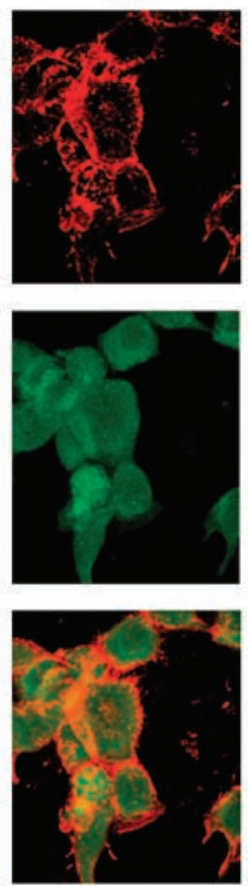

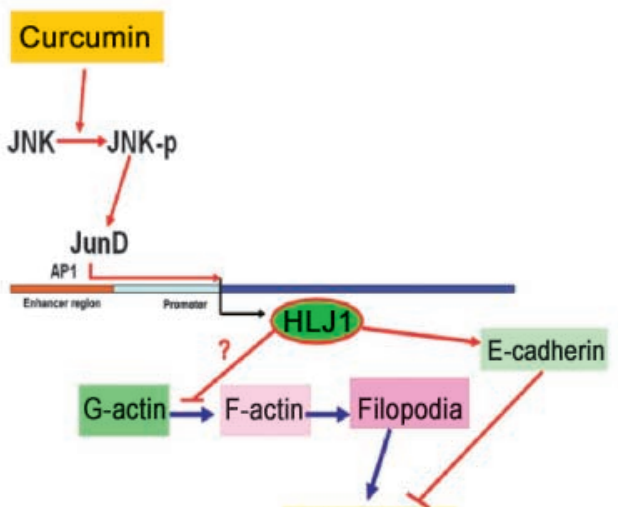

Cell migration

and invasion<smiles>C=CCCC</smiles>

Metastasis

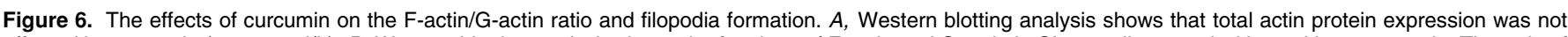

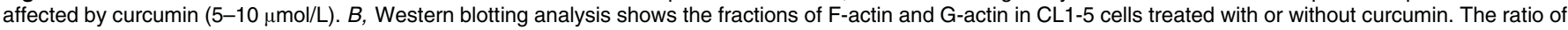

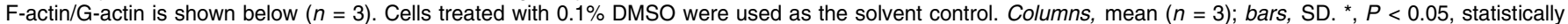
significant compared with the vehicle-treated control. These results are representative of three independent experiments. $C$, CL1-5 cells treated with or without

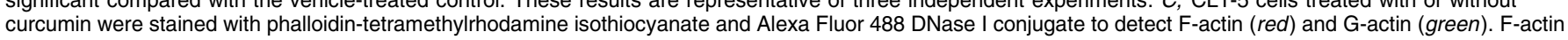
labeling with phalloidin-tetramethylrhodamine isothiocyanate reveals that CL1-5 cells exhibit numerous filopodia, whereas the curcumin-treated cells exhibit fewer filopodia fibers. $D$, the hypothetical mechanism by which curcumin causes HLJ1 induction and related signaling events during the drug's anti-invasive effects.

is involved in various biological processes, including normal cell growth and cancer development (34). Curcumin has been suggested to inhibit tumor growth through an inhibition of AP-1 activation (35). However, in this study, we found that curcumin significantly and concentration-dependently induced JunD expression and it could positively enhance the promoter activity of $H L J 1$ via AP-1 binding site. JunD is a versatile AP-1 component and is diverse from other AP-1 components in transcription regulation and cellular function (36). Previous evidence has shown that AP-1 complexes enriched with c-Jun and JunB may result in morphologic alterations and anchorage-independent cell growth, whereas complexes enriched with JunD had an antiproliferative effect (37). The induction of JunD by curcumin has also been reported in a previous study, which showed that curcumin exposure could up-regulate JunD expression and may lead to an increase in the enzymes involved in glutathione synthesis in HBE1 cells (38), the other JunD 
downstream gene, ferritin $H$ mRNA expression, can be transcriptionally regulated by curcumin $(36,39)$. JunB and JunD are able to bind to the putative AP-1 site in the HLJI enhancer and the expression of HLJ1 is positively correlated with JunB and JunD expression in a dose-dependent manner (25). Therefore, we suggest that HLJ1 may be regulated by curcumin through JunD induction and that this curcumin-induced JunD expression may have the tumor suppressor-like effects. This hypothesis is further supported by other recent studies, which have shown that specific AP-1 proteins, such as Fra-1, c-Fos, JunB and JunD, have tumor suppressor activity and that these effects depend on the antagonistic activities of the different Jun proteins, the tumor type, the tumor stage, and the genetic background $(25,34,40)$. Previous evidences showed that the regulation of JunD expression diverges from the well-characterized growth factor-inducible pattern of the c-jun early response genes and AP-1 autoregulation (36). Herein, we report that curcumin might regulate HLJ1 through modulating the JunD composition of the AP-1 transcription factor complex. Indeed, more studies are needed to clarify the AP-1 dimerization pattern and the activation of specific tumor suppressors in different cells and tissues.

E-cadherin, as the key component for adherence junctions between epithelial cells, has been investigated for its roles in tumorigenesis and as an invasion suppressor molecule in carcinoma cells (41). E-cadherin has also been suggested to be involved in epithelial-mesenchymal transition, a process associated with loss of cell-cell adhesion and epithelial polarity during cancer development and progression (42). Tumor cells with limited E-cadherin expression are more likely to detach from a tumor mass, resulting in a poor prognosis. This has been suggested to be an independent prognostic factor for NSCLC survival $(41,43)$. Our previous study indicated that HLJ1 might regulate cell invasion through E-cadherin (18), and herein, we have confirmed that curcumin is able to regulate E-cadherin expression in the previous finding (44); furthermore, we have also identified that this effect would seem to be at least partly mediated through HLJ1 and results in an inhibition of cancer cell invasion.

In this study, we found that the curcumin-treated cells showed a higher level of HLJ1 expression with a decreased F/G actin ratios and an aggregation of actins. Although, some HSPs have been suggested to be involved in cytoskeleton arrangement and play important roles in cell growth and motility regulations. For example, the major components of the intermediate filaments of simple epithelia, keratins $8 / 18$, have been reported to directly bind with Mrj, a DnaJ/Hsp40 family protein (28). Our previous study found that the Hsp40-like protein, HLJ1, Hsp27, and Hsp70 were significantly increased by curcumin (7). These results suggest that the HSPs may play a role and can explain some pharmacologic effects of curcumin. Although we did find the actin polymerization was affected by curcumin, whether this event was HLJ1 dependent or independent still need to be evaluated.

The key finding of this study is that it provides evidence supporting the idea that curcumin is able to up-regulate the expression of the tumor suppressor HLJ1 by transcriptionally activating its enhancer. This indicates that the anti-invasive and antimetastasis effects of curcumin are likely to be mediated through the induction of HLJ1, at least in part. Figure $6 D$ summarizes our hypothetical signaling pathways for curcumin, its regulation of HLJ1 expression, and its inhibition of cancer cell invasion. Furthermore, curcumin is able to increase JunD expression, stimulate HLJI enhancer activity, and trigger the expression of HLJ1, which would seem to subsequently reduce filopodia formation and up-regulate $\mathrm{E}$ cadherin expression. These effects ought to restrain cancer cells from invasion and metastasis.

Based on the molecular heterogeneity and complexity of the signaling pathways involved in cancer development, multiple targets therapy may be a winning strategy for anticancer treatment (19, 29). According to this study and our previous findings, curcumin could inhibit cancer cell migration and invasion, not only through the HLJ1/E-cadherin induction, but also involve the inhibition of MMP14 mRNA and protein expression, as well as the enzyme activities of MMP2 and MMP9 (7). These evidences strengthen the possibility for that curcumin may have the potential as a multitarget drug in anticancer therapy because this drug is able to target diverse mechanisms involved in the cell cycle, apoptosis, angiogenesis, invasion, and metastasis (1, 29-32). This study further suggests that curcumin may be a template for new antitumor drug developments that are able to target the tumor suppressor HLJ1.

\section{Disclosure of Potential Conflicts of Interest}

No potential conflicts of interest were disclosed.

\section{Acknowledgments}

Received 12/19/2007; revised 6/6/2008; accepted 7/15/2008

Grant support: National Science Council (93-2314-B-010-061-) and the National Science and Technology Program for Agricultural Biotechnology [96AS-1.2.1-ST-al(31) and 97AS-1.2.1-ST-al], and there was also support from a grant of the Ministry of Education, Aim for the Top University Plan.

The costs of publication of this article were defrayed in part by the payment of page charges. This article must therefore be hereby marked advertisement in accordance with 18 U.S.C. Section 1734 solely to indicate this fact.

We thank Dr. Ralph Kirby for his excellent editing and the Microarray Core of National Taiwan University for their technical support.

\section{References}

1. Menon LG, Kuttan R, Kuttan G. Anti-metastatic activity of curcumin and catechin. Cancer Lett 1999; 141:159-65.

2. Chen HW, Huang HC. Effect of curcumin on cell cycle progression and apoptosis in vascular smooth muscle cells. Br J Pharmacol 1998;124:1029-40.

3. Aggarwal S, Ichikawa H, Takada Y, Sandur SK, Shishodia S, Aggarwal BB. Curcumin (diferuloylmethane) down-regulates expression of cell proliferation and antiapoptotic and metastatic gene products through suppression of $\mathrm{I} \kappa \mathrm{B} \alpha$ kinase and Akt activation. Mol Pharmacol 2006;69:195-206.

4. Kim SY, Jung SH, Kim HS. Curcumin is a potent broad spectrum inhibitor of matrix metalloproteinase gene expression in human astroglioma cells. Biochem Biophys Res Commun 2005;337:510-6.

5. Aggarwal BB, Kumar A, Bharti AC. Anticancer potential of curcumin: preclinical and clinical studies. Anticancer Res 2003;23:363-98.

6. Cheng AL, Hsu CH, Lin JK, et al. Phase I clinical trial of curcumin, a chemopreventive agent, in patients with high-risk or pre-malignant lesions. Anticancer Res 2001; 21:2895-900.

7. Chen HW, Yu SL, Chen JJ, et al. Anti-invasive gene expression profile of curcumin in lung adenocarcinoma based on a high throughput microarray analysis. Mol Pharmacol 2004;65:99-110.

8. Chen JJ, Peck K, Hong TM, et al. Global analysis of gene expression in invasion by a lung cancer model. Cancer Res 2001;61:5223-30.
9. Miernyk JA. The J-domain proteins of Arabidopsis thaliana: an unexpectedly large and diverse family of chaperones. Cell Stress Chaperones 2001;6:209-18. 10. Jindal S. Heat shock proteins: applications in health and disease. Trends Biotechnol 1996;14:17-20.

11. Buchner J. Supervising the fold: functional principles of molecular chaperones. FASEB J 1996;10:10-9.

12. Van 't Veer LJ, Dai H, van de Vijver MJ, et al. Gene expression profiling predicts clinical outcome of breast cancer. Nature 2002;415:530-6.

13. Calderwood SK, Khaleque MA, Sawyer DB, Ciocca DR. Heat shock proteins in cancer: chaperones of tumorigenesis. Trends Biochem Sci 2006;31:164-72.

14. Ciocca DR, Calderwood SK. Heat shock proteins in cancer: diagnostic, prognostic, predictive and treatment implications. Cell Stress Chaperones 2005;10:86-103. 
15. Borges JC, Fischer H, Craievich AF, Ramos CH. Low resolution structural study of two human HSP40 chaperones in solution. DJAl from subfamily A and DJB4 from subfamily $B$ have different quaternary structures. J Biol Chem 2005;280:13671-81.

16. Venter JC, Adams MD, Myers EW, et al. The sequence of the human genome. Science 2001;291:1304-51.

17. Tsai MF, Wang CC, Chang GC, et al. A new tumor suppressor DnaJ-like heat shock protein HLJ1 and survival of patients with non-small cell lung carcinoma. J Natl Cancer Inst 2006;98:825-38.

18. Wang CC, Tsai MF, Hong TM, et al. The transcriptional factor YY1 upregulates the novel invasion suppressor HLJl expression and inhibits cancer cell invasion. Oncogene 2005;24:4081-93.

19. Albini A, Pfeffer U. A new tumor suppressor gene: invasion, metastasis and angiogenesis as potential key targets. J Natl Cancer Inst 2006;98:825-38.

20. Aggarwal BB, Shishodia S, Takada Y, et al. Curcumin suppresses the paclitaxel-induced nuclear factor- $k \mathrm{~B}$ pathway in breast cancer cells and inhibits lung metastasis of human breast cancer in nude mice. Clin Cancer Res 2005;11:7490-8.

21. Singh S, Khar A. Biological effects of curcumin and its role in cancer chemoprevention and therapy. Anticancer Agents Med Chem 2006;6:259-70.

22. Chu YW, Yang PC, Yang SC, et al. Selection of invasive and metastatic subpopulations from a human lung adenocarcinoma cell line. Am J Respir Cell Mol Bio 1997;17:353-60.

23. Chen JJ, Yao PL, Yuan A, et al. Up-regulation of tumor interleukin-8 expression by infiltrating macrophages: its correlation with tumor angiogenesis and patient survival in non-small cell lung cancer. Clin Cancer Res 2003;9:729-37.

24. Bieche I, Onody P, Laurendeau I, et al. Real-time reverse transcription-PCR assay for future management of ERBB2-based clinical applications. Clin Chem 1999; 45:1148-56.
25. Wang CC, Tsai MF, Dai TH, et al. Synergistic activation of the tumor suppressor, HLJl, by the transcription factors YY1 and activator protein 1. Cancer Res 2007;67:4816-26.

26. Cramer LP, Briggs LJ, Dawe HR. Use of fluorescently labeled deoxyribonuclease I to spatially measure G-actin levels in migrating and non-migrating cells. Cell Moti Cytoskeleton 2002;51:27-38.

27. Gavara N, Sunyer R, Roca-Cusachs P, Farre R, Rotge $\mathrm{M}$, Navajas D. Thrombin-induced contraction in alveolar epithelial cells probed by traction microscopy. J App Physiol 2006;101:512-20.

28. Izawa I, Nishizawa M, Ohtakara K, Ohtsuka K, Inad $\mathrm{H}$, Inagaki M. Identification of Mrj, a DnaJ/Hsp40 family protein, as a keratin $8 / 18$ filament regulatory protein. Biol Chem 2000;275:34521-7.

29. Kuttan G, Kumar KB, Guruvayoorappan C, Kuttan R Antitumor, anti-invasion and antimetastatic effects of curcumin. Adv Exp Med Biol 2007;595:173-84.

30. Lin JK. Molecular targets of curcumin. Adv Exp Med Biol 2007;595:227-43.

31. Narayan S. Curcumin, a multi-functional chemopreventive agent, blocks growth of colon cance cells by targeting $\beta$-catenin-mediated transactivation and cell-cell adhesion pathways. J Mol Histol 2004; 35:301-7.

32. Kunnumakkara AB, Guha S, Krishnan S, Diagaradjane P, Gelovani J, Aggarwal BB. Curcumin potentiate antitumor activity of gemcitabine in an orthotopic model of pancreatic cancer through suppression of proliferation, angiogenesis and inhibition of nuclear factor-кB-regulated gene products. Cancer Res 2007;67: 3853-61.

33. Lamb J, Crawford ED, Peck D, et al. The Connec tivity Map: using gene-expression signatures to connect small molecules, genes and disease. Science 2006;313 1929-35.

34. Reddy SP, Mossman BT. Role and regulation of activator protein-1 in toxicant-induced responses of the lung. Am J Physiol Lung Cell Mol Physiol 2002;283: L1161-78.

35. Huang TS, Lee SC, Lin JK. Suppression of c-Jun/AP-1 activation by an inhibitor of tumor promotion in mouse fibroblast cells. J Biol Chem 1991;88:5292-6.

36. Hernandez JM, Floyd DH, Weilbaecher KN, Green PL, Boris-Lawrie K. Multiple facets of junD gene expression are atypical among AP-1 family members. Oncogene. Epub 2008 Apr 21. [PMID: 18427548].

37. Leaner VD, Kinoshita I, Birrer MJ. AP-1 complexes containing cJun and JunB cause cellular transformation of Ratla fibroblasts and share transcriptional targets. Oncogene 2003;22:5619-29.

38. Dickinson DA, Iles KE, Zhang H, Blank V, Forman HJ Curcumin alters EpRE and AP-1 binding complexes and elevates glutamate-cysteine ligase gene expression. FASEB J 2003;17:473-5.

39. Jiao Y, Wilkinson J IV, Christine Pietsch E, et al. Iron chelation in the biological activity of curcumin. Free Radic Biol Med 2006;40:1152-60.

40. Eferl R, Wagner EF. AP-1: a double-edged sword in tumorigenesis. Nat Rev Cancer 2003;11: 859-68.

41. Bremnes RM, Veve R, Hirsch FR, Franklin WA. The Ecadherin cell-cell adhesion complex and lung cancer invasion, metastasis and prognosis. Lung Cancer 2002;36:115-24.

42. Kang Y, Massague J. Epithelial-mesenchymal transitions: twist in development and metastasis. Cell 2004; 118:277-9.

43. Bremnes RM, Veve R, Gabrielson E, et al. Highthroughput tissue microarray analysis used to evaluate biology and prognostic significance of the E-cadherin pathway in non-small-cell lung cancer. J Clin Oncol 2002;20:2417-28.

44. Ray S, Chattopadhyay N, Mitra A, Siddiqi M, Chatterjee A. Curcumin exhibits antimetastatic properties by modulating integrin receptors, collagenase activity and expression of $\mathrm{Nm} 23$ and E-cadherin. J Environ Pathol Toxicol Oncol 2003;22:49-58. 